\title{
Commentary
}

JSARD

ISSN: 2470-850X Online

Vol. 4, Issue 1 (2019), pp. 39-41

ISARD.org

\section{The Value in Pursuing the EdD}

\author{
John B. Stark, California State University, Bakersfield
}

\begin{abstract}
With the pressure to continue professional development in the P-12 environment, typically via additional educational degrees, many have exhausted the masters degree-level training and are looking at the doctoral level of degrees. However, considerations of the amount of time and effort involved in pursuing doctoral level degrees, the financial costs of the work, and confusion around which type of degree to pursue, have combined to create barriers in moving forward. This article is meant to assist in making this decision by talking about the differences between $\mathrm{PhD}$ and EdD programs and by advocating for a choice of the EdD. The advantages and value of EdD programs are discussed.
\end{abstract}

Keywords: EdD, doctoral work, graduate work, continuing professional education

While the notion of continuing professional education is commonplace for educators in the Kindergarten through Grade 12 (K-12) ranks, most practitioners plateau at a master's degree (and sometimes, several). There is, however, a higher degree available--one that does not mean putting your career on pause and relocating, as is often the case with many Doctorate of Philosophy in Education $(\mathrm{PhD})$ programs. That alternative is the practitioner doctorial degree known as the Educational Doctorate (EdD).

There are several differences between a $\mathrm{PhD}$ and an EdD, with the most important being the focus of the degree. While a PhD teaches candidates to become scientists committed to pushing the bounds of their basic knowledge of the world around them, the $\mathrm{EdD}$, a degree of practice, focuses on developing candidates who can solve more immediate, real-world problems in their operational world. As a result of these fundamental differences in end goals, the $\mathrm{PhD}$ is generally a four-plus year program with a lot of time spent on developing intensive statistical methods and research skills. Conversely, an EdD is typically a three -year program that focuses on developing practical knowledge and quantitative and qualitative skills required to solve the challenging operational problems typically confronted by a modern K-12 leader.

And just as there are differences, there are also similarities. Both of these degrees are considered terminal, meaning that they are at the top of the degree pyramid. Both of the programs require a dissertation, which is an extended research effort reported in a thick tome. Both programs are selective in their recruitment, with small class sizes and a lot of close work with faculty. Finally, both of the programs are a major leap above masters-level work, in that they take the candidate's understanding beyond the textbooks and research articles to reflect on and understand the workings of the science behind the literature.

Given this understanding of the two terminal degree options, there are two important considerations: first, whether pursuing a doctoral degree is relevant for a K-12 practitioner and worth the investment, and second, contingent upon the first, which degree is best to pursue. For many, the answer is not only a resounding "yes" for pursuing a doctoral degree, but there is also a clear argument that the $\mathrm{EdD}$, the practitioner-oriented doctoral degree, is actually the better option. Several key values of the EdD degree help to support this conclusion.

One important value of EdD programs is that they can help a candidate better prepare for the strategic challenges facing K-12 education. This degree is not only grounded in the controversies over local control and the budget battles being waged across the nation for K-12 education, but the degree programs also delve into the philosophies at play in the fight over the very soul of K-12 institutions (Beers, 2013). As more and more focus has been placed on how students are performing on a given test than what is being learned, practitioners need to be prepared to both understand and engage in this debate. As Beer 
(2013) notes, it is no longer about the child and working to enhance her potential; the focus has narrowed to a very "profit-oriented" goal of passing tests. While one may acknowledge that "learning" must occur and that accountability for ensuring that learning is nothing to be afraid of, this is a difficult balance that most of our K-12 practitioners have not been adequately prepared for.

Further, EdD degree programs are available to answer the growing volume of calls for efforts to reconcile the material and idealistic views of the world (Anderson, 2018). An EdD program focuses learning on the ideas, strategies, and policies that direct our current educational efforts. These programs assist candidates in identifying the specific laws, policies, and directives behind current operational practices by helping them to understand the philosophies and choices being made in promulgating these directives and in exposing them to a variety of alternative viewpoints or "frames" (Bolman \& Gallos, 2011). EdD candidates are taught to make "sense" out of their operational realities (Weick, 1995). With this understanding, and the development of insights into the drivers and constraints of organizational structures that they learn in their programs, EdD graduates are prepared to effect change in their organizations and respond to the many and often conflicting demands of their constituents.

However, candidates in EdD programs are not just given tools to try and understand in a sterile, disconnected context. Another value of these programs is the practical application of the knowledge and skills learned. EdD programs use field-based exercises to allow students to experience the application of ideas and skills. The candidates then develop a dissertation that typically involves an action learning format in which a real problem is identified, a plan is developed and applied, and the results are measured to determine the efficacy of the intervention. Thus, these programs allow candidates to produce real world value immediately. In my local institution, we have seen students make meaningful contributions to such perplexing problems as how to deal with students performing below grade-level, how to mitigate the effects of socio-economic barriers in student learning, and how to address chronically low performance among minority groups.

A final major benefit when considering the worth of an EdD is the professional development that such programs offer. The continuing and growing need for professional development is of major concern for today's K-12 practitioners (Rickard, 2019). We need greater focus on attracting and training qualified applicants to our educational and administrative ranks (Taylor and Youngs, 2018). And beyond the efforts to recruit and train educators and administrators, Rickard (2019) informs us of the need to further develop the personnel that we have. Our K12 practitioners need to be better prepared for the multiple roles and growing demands placed upon them (Shepherd, Fowler, McCormick, Wilson, \& Morgan, 2016).

In answering the demands described above, an EdD program offers both general and specific assistance to candidates. The general experience and exercises in expanded thinking are of value across the spectrum of administrators and teachers at all levels of the K-12 experience. Exposure to current topics and to topics on the horizon of educational policy is common, as is diving into strategies for dealing with the cultural challenges, curriculum issues/options, and organizational theories guiding the modern educational institution. Other general topics include development of a clear understanding of the research process, statistical methods, and qualitative research tools needed for both program evaluation and the action-oriented research needed to tackle current challenges. In addition, most programs work on the professional growth of each candidate to facilitate their ability to impact their organizations at whatever level they reside. This latter area includes developing managerial skills to be used by all candidates, regardless of position, in enhancing communication, conflict resolution, teamwork, and leadership skills. This area of development also assists practitioners in understanding and balancing the multi-faceted roles in their lives.

In terms of the more specific knowledge and skills that EdD programs afford administrators, topics typically include budget and resource management, as well as generating an understanding of human resource strategies and policies. Knowledge in these key areas facilitate the candidate in becoming a knowledgeable consumer and director of both accounting and human resources output, rather than a passive instrument of their directives. For teachers, class topics and activities further develop understanding of students, parents, and the communities in which all are embedded, as well as techniques for engaging and directing programs for enhanced outcomes. The process of deep learning and "rolling back the curtain" on key educational topics and theories can really generate a spark that inspires our learners to become both committed consumers of learning, as well as articulate advocates for education in general. 
All in all, an Educational Doctorate degree provides a unique foundation for clearer insights into and deeper understanding of the problems confronting the K-12 world. The graduates are better prepared for the challenges that they confront, and they are acknowledged leaders in dealing with these issues. Holders of an EdD can be found at all levels of the K12 world, from primary to middle schools, and on to high schools. They are found in the classrooms, at the school administrative levels, and in district leadership. Wherever leaders are needed, EdD holders will likely be found. So, is there value in pursuing an EdD? Just ask an EdD holder in your organization. They are there, and they are likely at the forefront of the change and growth work in your organization.

\section{References}

Anderson, T. (2018). Sophic education: Where is your treasure? Education and Culture, 34(1), 41-59.

Beers, K. (2013). What matters most: Considering the issues and the conversations we need to have. Journal of Adolescent \& Adult Literacy, 57(4), 265269.

Bolman, L.G., \& Gallos, J.V. (2011). Reframing academic leadership. San Francisco, CA: Jossey-Bass.

Rickard, A. (2019). An interview with CEC president Mary Lynn Boscardin. Teaching Exceptional Children, 51(3), 253-255.

Shepherd, K., Fowler, S., McCormick, J., Wilson, C., \& Morgan, D. (2016). The search for role clarity. Teacher Education \& Special Education, 39(2) 83-97.

Taylor, S., Youngs, H. (2018). Leadership succession: Future proofing pipelines. Journal of Deaf Studies $\mathcal{E}$ Deaf Education, 23(1), 71-81.

Weick, K.E. (1995). Sensemaking in Organizations. Thousand Oaks, Ca: Sage.

\section{Author}

John B. Stark, PhD, is Director of the Doctoral Program in Educational Leadership, California State University, Bakersfield; 9001 Stockdale Hwy, Bakersfield, CA 93311; jstark@csub.edu. His research interests include work in conflict resolution, the development of trust, and the pedagogy of management ideas and skills. 